\title{
Secukinumab: The Anti-IL-17A Biologic for the Treatment of Psoriasis
}

\author{
Maria Concetta Fargnoli \\ Department of Dermatology, University of L'Aquila, L'Aquila, Italy
}

Interleukin-17 (IL-17) is a pro-inflammatory cytokine mainly produced by T helper 17 (Th17) lymphocytes. It is involved in inflammatory responses, promoting neutrophilic chemotaxis and angiogenesis. Keratinocytes are induced by IL-17 to express chemokines that promote recruitment of myeloid dendritic cells, Th17 cells, and neutrophils at the site of the lesion [1-4]. Several studies have demonstrated that IL-17 is pivotal in the pathogenesis of psoriasis, and thus represents a crucial therapeutic target [1,5].

Secukinumab is a fully human immunoglobulin G1 kappa antibody, which targets IL-17A [6]. Secukinumab was the first anti-IL-17 biologic to be approved by the US Food and Drug Administration and the European Medicines Agency for the treatment of moderate-to-severe psoriasis and psoriatic arthritis (PsA) in adult patients [7].

Phase III trials compared secukinumab 150 and $300 \mathrm{mg}$, administered once weekly for 5 weeks, then every 4 weeks, with placebo and etanercept, and demonstrated that secukinumab is superior in terms of efficacy to etanercept, with similar safety in patients with moderate-tosevere psoriasis. A 75\% reduction in the Psoriasis Area and Severity Index (PASI) score (PASI75) at week 12 was found in $81.6 \%$ of patients treated with secukinumab $300 \mathrm{mg}$ in the ERASURE study and $77.1 \%$ in the FIXTURE study, compared with $44.0 \%$ of patients receiving etanercept [8].

A "head-to-head" study comparing secukinumab and ustekinumab (anti-IL-12/IL-23 monoclonal antibody) in moderate-to-severe psoriasis showed that secukinumab is superior to ustekinumab in clearing skin lesions and improving quality of life, with comparable safety. A $90 \%$ reduction in the PASI score (PASI90) at week 52 was observed in $74.9 \%$ of patients treated with secukinumab and in $60.6 \%$ of those treated with ustekinumab [9]. Bagel et al. [10] reported similar results in the CLARITY study, where patients were randomized to receive subcutaneous secukinumab $300 \mathrm{mg}$ or ustekinumab.

Additional studies demonstrated that secukinumab was effective for the treatment of PsA and for difficult-to-treat variants of psoriasis such as palmoplantar psoriasis [11,12]. 
Real-life studies including different patient populations, patients with variable disease severity, and multiple concomitant diseases confirmed the efficacy and safety results of previous randomized trials with secukinumab [13-16].

The articles of this supplement issue present an update on the use of secukinumab in clinical practice for patients with psoriasis and PsA, enriched by the experience of the authors. Some special clinical scenarios are discussed to promote the correct use of the drug in challenging patients, such as those with cancer, infections and/or contraindication to antibiotic prophylaxis and obesity.

Campanati et al. [this issue] report their clinical experience in a patient affected by severe erythrodermic psoriasis with Kaposi's varicelliform eruption, successfully treated with secukinumab for 1 year. Psoriasis cleared and no recurrence of Kaposi's varicelliform eruption occurred.

In Ribero et al. [this issue], the authors describe 12 patients with moderate-to-severe plaque psoriasis eligible for systemic treatment and affected by latent tuberculosis infection. They received secukinumab without previous prophylaxis because of a clinical contraindication in 11 cases and refusal in 1 patient. None of them developed tuberculosis reactivation.

Concerning safety, secukinumab is well tolerated and did not show an increased risk of malignancy in clinical studies. In the case report described by Gambardella [this issue], secukinumab was effectively used in a psoriatic patient with a previous history of cancer.

Kostaki et al. [this issue] suggest that the combination of secukinumab with systemic therapy may be an effective and tolerated option for the management of severe psoriasis. In their case report describing a patient with a long-standing, moderate-to-severe, recalcitrant plaque psoriasis and PsA, treatment was optimized by adding methotrexate to secukinumab.

Tiberio et al. [this issue] show how secukinumab can be prescribed in patients with psoriasis in all body weight groups, even in the highest where usually clinical response shows a slight downward trend. They report on obese patients affected by psoriasis and PsA successfully treated with secukinumab.

\section{Acknowledgement}

Laura Brogelli, PhD, on behalf of Content Ed Net, provided editorial assistance.

\section{Disclosure Statement}

The author has no conflicts of interest to declare. The author declares that, as far as she knows, the studies were conducted in accordance with the World Medical Association Declaration of Helsinki and that the patients have given their written informed consent to publish their case, including images.

\section{Funding Sources}

Editorial assistance was funded by Novartis Farma Italy. 


\section{References}

1 Chiricozzi A. Pathogenic role of IL-17 in psoriasis and psoriatic arthritis. Actas Dermosifiliogr. 2014 Oct;105 Suppl 1:9-20.

2 Ghoreschi K, Laurence A, Yang XP, Hirahara K, O’Shea JJ. T helper 17 cell heterogeneity and pathogenicity in autoimmune disease. Trends Immunol. 2011 Sep;32(9):395-401.

3 Zaba LC, Fuentes-Duculan J, Eungdamrong NJ, Abello MV, Novitskaya I, Pierson KC, et al. Psoriasis is characterized by accumulation of immunostimulatory and Th1/Th17 cell-polarizing myeloid dendritic cells. J Invest Dermatol. 2009 Jan;129(1):79-88.

4 Nograles KE, Zaba LC, Guttman-Yassky E, Fuentes-Duculan J, Suárez-Fariñas M, Cardinale I, et al. Th17 cytokines interleukin (IL)-17 and IL-22 modulate distinct inflammatory and keratinocyte-response pathways. Br J Dermatol. 2008 Nov;159(5):1092-102.

5 Chen Y, Qian T, Zhang D, Yan H, Hao F. Clinical efficacy and safety of anti-IL-17 agents for the treatment of patients with psoriasis. Immunotherapy. 2015;7(9):1023-37.

6 Tausend W, Downing C, Tyring S. Systematic review of interleukin-12, interleukin-17, and interleukin-23 pathway inhibitors for the treatment of moderate-to-severe chronic plaque psoriasis: ustekinumab, briakinumab, tildrakizumab, guselkumab, secukinumab, ixekizumab, and brodalumab. J Cutan Med Surg. 2014 May-Jun;18(3):156-69.

7 Sanford M, McKeage K. Secukinumab: first global approval. Drugs. 2015 Feb;75(3):329-38.

8 Langley RG, Elewski BE, Lebwohl M, Reich K, Griffiths CE, Papp K, et al.; ERASURE Study Group; FIXTURE Study Group. Secukinumab in plaque psoriasis—results of two phase 3 trials. N Engl J Med. 2014 Jul;371(4):326-38.

9 Blauvelt A, Reich K, Tsai TF, Tyring S, Vanaclocha F, Kingo K, et al. Secukinumab is superior to ustekinumab in clearing skin of subjects with moderate-to-severe plaque psoriasis up to 1 year: results from the CLEAR study. J Am Acad Dermatol. 2017 Jan;76(1):60-69.e9.

10 Bagel J, Nia J, Hashim PW, Patekar M, de Vera A, Hugot S, et al. Secukinumab is Superior to Ustekinumab in Clearing Skin in Patients with Moderate to Severe Plaque Psoriasis (16-Week CLARITY Results). Dermatol Ther (Heidelb). 2018 Dec;8(4):571-9.

11 Mease P, McInnes IB. Secukinumab: a new treatment option for psoriatic arthritis. Rheumatol Ther. 2016 Jun;3(1):5-29.

12 Gottlieb A, Sullivan J, van Doorn M, Kubanov A, You R, Parneix A, et al. Secukinumab shows significant efficacy in palmoplantar psoriasis: results from GESTURE, a randomized controlled trial. J Am Acad Dermatol. 2017 Jan;76(1):70-80.

13 Georgakopoulos JR, Ighani A, Zhou LL, Yeung J. Efficacy and safety of secukinumab in treating moderate to severe plaque psoriasis in two real-world Canadian dermatology clinics: a multicenter retrospective study. J Eur Acad Dermatol Venereol. 2018 Jan;32(1):e32-4.

14 Magnano M, Loi C, Patrizi A, Sgubbi P, Balestri R, Rech G, et al. Secukinumab in multi-failure psoriatic patients: the last hope? J Dermatolog Treat. 2018 Sep;29(6):583-5.

15 Schwensen JF, Clemmensen A, Sand C, Gniadecki R, Skov L, Zachariae C, et al. Effectiveness and safety of secukinumab in 69 patients with moderate to severe plaque psoriasis: A retrospective multicenter study. Dermatol Ther (Heidelb). 2017 Nov;30(6):e12550.

16 Galluzzo M, Talamonti M, De Simone C, D'Adamio S, Moretta G, Tambone S, et al. Secukinumab in moderateto-severe plaque psoriasis: a multi-center, retrospective, real-life study up to 52 weeks observation. Expert Opin Biol Ther. 2018 Jul;18(7):727-35. 